\title{
Practice of Breast Self-Examination and Associated Factors Among Female Nurses of Hawassa University Comprehensive Specialized Hospital, South Ethiopia, 2018
}

\author{
Wegene Jemebere (WJ) \\ School of Nursing, Faculty of Health Sciences, College of Medicine and Health Sciences, \\ Hawassa University, Ethiopia
}

\begin{abstract}
Background: Breast cancer is the most commonly diagnosed cancer in women and it is the leading cause of cancer related death worldwide. Despite most of the cases found at developed countries, majority of death occur in low income countries including Ethiopia. Routine breast self-examination is important for early detection to augment prevention of breast cancer by $50 \%$ and reduce premature death of women. In active role in creating breast cancer awareness through education, nurses need to have a sound knowledge base and adequate practical skills in the field of breast cancer prevention. The aim of this study was to assess practice of breast self- examination (BSE) and associated factors among nurses.

Methods: A hospital based descriptive cross-sectional study was conducted from March to April 2018 on a sample of 180 female nurses. Pretested and structured questionnaire was used to collect the data. Data entry was done using EPI Info 3.5.4 and exported to SPSS version 20.0 software package for analysis. Bivariate and multivariate analyses were performed with logistic regression to measure the association between dependent and independent variables.

Results: Total of 180 nurses were interviewed with a response rate of $91.8 \%$. This study revealed that $(71.2 \%)$ of nurses ever practiced BSE. From those nurses practiced BSE, only (28.1\%) regularly; (16.4\%) monthly (right response) and $(32.0 \%)$ of a week after menses. Seven of them detected a breast mass/lump and only (16.4\%) of nurses have taught BSE technique to their clients. Educational status of the nurses (AOR and 95\% CI: 2.91; 1.74, 4.85 ) and family history of breast cancer (AOR and 95\% CI: 5.2; 2.34, 8.15 were significantly associated with BSE practice.

Conclusion: This study discovered severe gap about the correct practice of BSE among female nurses. The hospital and ministry of health of Ethiopia have to give regular education and training on BSE especially how to practice BSE correctly.
\end{abstract}

Keywords: Nurse, breast cancer, breast self-examination, Ethiopia.

DOI: $10.7176 / \mathrm{JHMN} / 66-07$

Publication date:September $30^{\text {th }} 2019$

\author{
List of abbreviations \\ WHO: World Health Organization \\ BSE: Breast Self-Examination \\ CBE: Clinical Breast Examination \\ BSc: Bachelor of Science \\ MSc: Masters of Science \\ IRB: Institutional Review Board of Hawassa University \\ SNNPR: Southern Nations Nationalities and Peoples Region \\ AOR: Adjusted Odds Ratio \\ COR: Crude Odds Ratio
}

\section{Background}

Breast cancer is the most commonly diagnosed cancer in women and the second leading cause of cancer related morbidity and deaths next to lung cancer. Every year's worldwide 1.15 million women are diagnosed with breast cancer and more than a half million die from this disease [1]. Despite the incidence of breast cancer is higher in the developed countries; the prevalence of death is higher than in developing countries [2].

Although breast cancer is thought to be a disease of the developed world, almost $50 \%$ of breast cancer cases and $58 \%$ of deaths occur in less developed countries [3].

Hospital records show that in Ethiopia there are more than 200,000 cancer cases per year where cervical \& breast cancers are the top two cancer types having a lion's share for the high women deaths in the country and most women with breast cancer still present very late and treatment outcomes are often not optimal [4].

The prevalence of breast cancer in women aged 15 and over in sub Saharan Africa was 23.5 per 100,000 women in 2008 [5] and breast cancer has increased by more than $20 \%$, while mortality has increased by $14 \%$ since 
$2008[6]$.

The incidence of breast cancer is alarmingly rising in Ethiopia. Despite around 10,000 Ethiopian women and men have breast cancer with thousands of more cases unreported as women living in rural areas often seek treatment from traditional healers before seeking help from the government health system [7].

BSE involves the woman herself looking at and feeling the breasts for lumps, shape, texture, size and contour. The purpose is to teach any woman about the topography of her breasts, know how her normal breasts feel and be able to identify changes [8].

Breast self-examination is a simple, inexpensive, non-invasive procedure makes women more "breast aware", which in turn may lead to an earlier diagnosis of breast cancer [9]. For younger women, BSE education and adherence are a gateway to health promotion behaviors which set the stage for adherence to clinical breast examination and mammography screening later in life [10].

Routine self-breast examinations are a fundamental method for early detection of breast cancer and treat at early stage to improve quality of life and survival [11]. A woman who performs BSE regularly and correctly is more motivated to seek medical attention, including clinical breast examination (CBE) and mammography when need arises [12]. Despite the advent of modern screening methods, more than $90 \%$ of cases of breast masses are detected by women themselves, stressing the importance of BSE [9].

Breast self-examination awareness and health seeking practices have been shown to be poor in many developing countries, necessitating the need for proper awareness programs [13]. In sub-Saharan Africa including Ethiopia, latest advanced detection techniques are not readily available for women breast cancer detection therefore BSE is one of the inexpensive and easy screening methods for early detection of breast cancer [14].

Therefore, even if there are some debates concerning the techniques used in performing BSE, the method is still considered as relevant, and is therefore recommended in developing countries where access to diagnostic and curative facilities may be a problem [15].

Thus, this research is essential and provides data about the practice of breast self-examination and associated factors among female nurses. The results of this study have huge importance as it may support nurses in scheduling health education for their clients and make them useful advertiser in the fight of breast cancer. In Ethiopia nurses take a lion's share to tackle breast cancer even at grass root level in the community. Also, from this research findings, health screening which include breast self-examination education to equip nurses with accurate knowledge and skills should be integrated as one of regular activities in Hawassa University comprehensive and specialized hospital program as well it will be an input for Ethiopia cancer prevention plan.

There is still insufficient published data concerning practice of breast self-examination and associated factors among female nurses in Ethiopia. Therefore, the aim of this study was to assess practice of breast self-examination and associated factors among female nurses of Hawassa University comprehensive specialized hospital, southern Ethiopia.

\section{Methods}

\section{Study design and setting}

A hospital based descriptive cross-sectional study was conducted from March to April 2018 among female nurses of Hawassa University comprehensive and specialized hospital.

Hawassa is situated at the eastern shore of Lake Hawassa and is located $275 \mathrm{~km}$ to south of Addis Ababa, the capital city of the country. Hawassa University comprehensive specialized hospital is located in south part of Hawassa town. Hawassa university comprehensive and specialized hospital has been treating patients from especially Sidama zone of SNNPR and from neighboring Oromia region. Currently the hospital has around 350 in-patient beds; different service giving units including secondary eye unit, physiotherapy unit, ENT unit, dermatology unit, pathology unit, Onchology unit and dental clinic. The hospital is also center for different initiated projects. The vision is to make the hospital a center of training and research for tropical diseases in addition to curative services.

\section{Sample size and sampling procedure}

The sample size was computed using a formula for calculating single population proportions, with $95 \%$ confidence level and 5\% level of accuracy. After adjustment, the calculated total sample size was 180 nurses.

Hawassa University comprehensive and specialized hospital was selected conventionally as it encompasses as many female nurses fit to the study and it is the only hospital gives breast cancer treatment in the south region of Ethiopia. Sampling frame of female nurses working at the time of data collection in the hospital has been prepared and study subjects were selected from the frame by using simple random sampling method.

\section{Data collection tools and procedures}

English version of structured self-administered questionnaire was adopted from similar studies in developing countries Nigeria [17, 18]; Sudan [19]; Morocco [20] and Wollega University of Ethiopia [21] used to collect information. Pre-testing was conducted on $5 \%$ of the sample size at Adare general hospital in Hawassa town and based on the result necessary amendments were made. Data were collected by four BSc nurses and training 
was given on the objective, relevance of the study, confidentiality of information, respondent rights, informed consent, and technique of interview and related issues prior to the start of data collection and were closely supervised during the data collection. The collected data were reviewed and checked for completeness before data entry.

\section{Statistical analysis}

Data entry was done by using EPI Info 3.5.4 and exported to SPSS version 20.0 software package for analysis. Descriptive statistics was used to see frequency, mean, standard deviation and percentages of the characteristics. Bivariate and multivariate analyses were performed with logistic regression to measure the association between dependent and independent variables to determine adjusted odds ratio (AOR).

\section{Ethics approval and consent to participate}

A written ethical clearance was obtained from the Institutional Review Board of Hawassa University, Hawassa, Ethiopia. Formal letter of cooperation was written to the Hawassa university comprehensive and specialized hospitals. After provision of sufficient information about the purpose of study, a verbal and written consent were obtained from all study participants. Participants were also informed that participation was on voluntary basis and they can withdraw from the study at any time if they are not comfortable about the questionnaire. To ensure the confidentiality of respondents, their names were not written on the questionnaire.

\section{Results}

\section{Socio demographic characteristics of the study participants}

A total of 180 nurses were participated with a response rate of $(91.8 \%)$. Majority of the respondents $(38.3 \%)$ were in the age range $21-25$ and almost two third of the respondents $(65.5 \%)$ served five years and less.

More than half of the study participants $(53.3 \%)$ were Orthodox in religion and $(57.3 \%)$ were diploma nurses. The dominant ethnicity was Amhara (40\%); most of nurses were married (58.8\%) and only (3.8\%) of them had history breast cancer in the family (Table1).

\section{Practice of breast self-examination}

This study revealed that (71.2\%) of nurses ever practiced BSE. Most of the study participants (92.2\%) practiced BSE for purpose of early detection and treatment of breast cancer and from 52 of them who not ever performed BSE, (73.1\%) didn't know the technique of BSE.

From those nurses perform BSE, only (28.1\%) regularly; (16.4\%) monthly (right response) and (32.0\%) of a week after menses (acceptable response).

Almost half of the study participants (47.6\%) used all position and (64.1\%) used all techniques of BSE while $(57 \%)$ of the respondents used palm and three middle fingers (best response) to palpate their breast.

Majority of nurses $(72.6 \%)$ have examined their breast for presence of mass (best response); 7 of them detected a breast mass/lump but 4 of them didn't consult physician; 2 of them mentioned fear of detecting something abnormal as a reason not to consult and only $(16.4 \%)$ of nurses have taught BSE technique to their clients (Table 2).

\section{Factors associated with BSE practice}

This study reviled that, educational status of the nurses $(\mathrm{AOR}=2.9195 \% \mathrm{CI}(1.74,4.85))$ and family history of breast cancer $(\mathrm{AOR}=5.295 \% \mathrm{CI}(2.34,8.15))$ were significantly associated with BSE practice (Table 3$)$.

\section{Discussion}

This study revealed that $(71.2 \%)$ of nurses ever practiced BSE. This finding was higher as compared to nursing students of Arab American University (37.1\%) [23]. The difference could be due to setting and variation in knowledge and skill about breast self-examination between students and experienced nursing staff in this study. But the finding was lower with the findings of a study from United Arab Emirate health professionals (84.4\%) [22]. The observed difference could be due to the difference in knowledge and skill among the study participants.

The major reasons not to perform BSE was not understanding the technique of BSE (73.1\%). Similar studies showed that lack of knowledge how to perform BSE was one of the major reasons among female undergraduate nursing students of Addis Ababa University Ethiopia [24] and among health extension workers of Gojam Ethiopia [25]. The result is indicating insufficient education about BSE in Ethiopian nursing colleges.

Only $(28.1 \%)$ of nurses perform BSE regularly in this study but still it was higher compared to Arab American University nursing students (4.1\%) [23] and Indian nurses of primary hospitals (15.6\%) [26]. The difference could be credited to the fact that nursing and health science students also nurses of primary hospitals did not receive yet in-depth breast cancer course like experienced nurses of specialized hospital. But the findings were higher among health professionals in Sao Polo Brazil (90.3\%) ([27], nurses of Poland (56.7\%) [28] and Nurses of United Arab Emirates $(61.5 \%)$ [22]. This could be due to the difference of educational level among the study participants and setting of the study area.

A small proportion (16.4\%) of the study participants practiced BSE monthly. This finding was similar to study done in Nigeria where only (23.9\%) of nurses examined their breasts on monthly basis [29] and comparable 
reports of low practice of monthly BSE have been reported among women in general [20]. This could be due to lack of accurate knowledge when to do breast self-examination.

This study identified that (68\%) of nurses didn't know BSE should be performed a week after menses. Similar finding was found in Ghana study, as (62\%) of nurses stated some days after menstruation [30] but it was higher in Saudi Arabia nurses as (46.8\%) of them aware that it should be performed a week after menses [31]. This is difference expected considering the fact that, disparity in knowledge and skill of BSE between African and Arabian nurses.

In this study, only (16.4\%) of nurses have taught BSE technique to their clients while (42.9\%) polish nurses educate women [28]. The difference may be one of the reason to unsatisfactory result of accurate BSE practice in this study. Different studies discovered that female health professionals whoever taught BSE to their clients were more likely to be engaged in practicing BSE [32; 33; 34].

This study showed that educational status of nurses was significantly associated with practice of BSE. Nurses with BSc and above were nearly 3 times more likely to practice BSE (AOR=2.81 95\% CI $(1.75,4.86)$ ) than diploma nurses. The finding was similar in a study done Ghana [30] and Saudi Arabia [35] nurses as level of education is a factor associated with practice toward BSE but in contrary to Nigeria study as there was no significant association was found between level of education and the practice of BSE [36]. The reason could be those nurses with bachelor degree and above have received detail education about breast cancer and BSE than diploma holders.

This study also identified that only (47.6\%) of nurses used all position of BSE while (58.9\%) Poland nurses performed the examination both in the standing and lying position [28]. The discrepancy might be due to difference in the study area as Poland nurses may have had better experience and knowledge on BSE than Ethiopians.

Family history of breast cancer was significantly associated with practice of BSE in this study as nurses with family history of breast cancer were 5 times more likely to practice BSE than nurses without (AOR=5.1 95\% CI $(2.33,8.14))$ which was consistent with a study done in Addis Ababa Ethiopia [24], Northwest Nigeria [37] and Kuwait [38]. According Kosgeroglu women with a positive family history of breast cancer had a better knowledge as well as higher frequency of BSE practice than those with a negative family history [39]. This could be due to fear of acquire a disease from a family make them cautious in noticing any change in their breast at early stage. Furthermore, this study didn't establish significant association between age, work experience, religion, ethnicity and marital status of nurses with practice of BSE.

\section{Conclusion}

This study discovered severe gap about the correct practice of BSE among female nurses. Even if this study discovered the ever practice of BSE is encouraging, it was not done regularly, monthly and a week after menses with unsatisfactory result in position and technique of BSE by most of nurses and this could be an obstacle to screening program and early diagnosis of breast cancer.

The major reason for not practicing BSE was insufficient knowledge and skill of the technique and the reason could be due to lack of adequate education and training of nurses on breast cancer in the studied hospital. Opportunity should therefore be sought in various health facilities to educate nurses who are supposed to be closer instructor to patients on breast cancer, its risk factors, symptoms, warning signs and how to detect it early by BSE.

\section{Recommendation}

In order to function as effective promoters of breast cancer control through early detection, nurses should possess the accurate knowledge and skill concerning breast cancer and its early detection methods. Nurses should adopt such protective screening measures especially BSE and act as role models for the female community.

I would like to recommend Hawassa University comprehensive specialized hospital and Federal ministry of health of Ethiopia have to give regular education and training on BSE especially how to practice BSE correctly as a readily accessible way to nurses because nurses should possess the accurate knowledge and skill concerning breast cancer and its early detection methods.

Further, encouraging the nurses who perform and teach BSE to their clients and increase the level of awareness by providing reading materials and ceremonies through the media or celebrating day's like breast cancer day may be helpful.

\section{Declaration}

\section{Ethics approval and consent to participate}

A written ethical clearance was obtained from the Institutional Review Board of Hawassa University, Hawassa, Ethiopia. Formal letter of cooperation was written to the Hawassa university comprehensive and specialized hospitals. After provision of sufficient information about the purpose of study, a verbal and written consent were obtained from all study participants. Participants were also informed that participation was on voluntary basis and they can withdraw from the study at any time if they are not comfortable about the questionnaire. To ensure the 
confidentiality of respondents, their names were not written on the questionnaire.

Consent for publication

Not applicable.

\section{Availability of data and materials}

All data generated or analyzed during this study are included in this published article [and its supplementary information files]. I send all which are available; there is no remaining data and materials.

Competent interests

The author declares no conflict of interest

Funding and sponsor ship

This research was funded by Hawassa University for academic staff's fund. The role of the funding body was to expense the cost for data collection, analysis and interpretation. The study design and manuscript were designed and written by author.

\section{Author contribution}

WJ conceived and designed the study, participated in data supervision, analyzed the data, drafted the manuscript. The author read and approved the final manuscript.

\section{Acknowledgement}

I would like to express my heartfelt thanks to Hawassa University to give this chance. My deep acknowledgement extends to concerned female nurse staffs of Hawassa University comprehensive and specialized hospital as study participants.

\section{Authors' information}

\section{Wegene Jemebere (WJ)}

School of Nursing, Faculty of Health Sciences, College of Medicine and Health Sciences, Hawassa University, Ethiopia.

Table 1: Socio-demographic characteristics of female nurse of Hawassa University comprehensive and specialized hospital, south Ethiopia, February $2018(\mathrm{n}=180)$.

\begin{tabular}{|c|c|c|}
\hline Variables $(n=180)$ & Frequency & Percentage \\
\hline \multicolumn{3}{|l|}{ Age } \\
\hline $15-20$ & 5 & 2.7 \\
\hline $21-25$ & 69 & 38.3 \\
\hline $26-30$ & 57 & 31.6 \\
\hline $31-35$ & 28 & 15.5 \\
\hline$>35$ & 21 & 11.6 \\
\hline \multicolumn{3}{|l|}{ Work experience } \\
\hline Less than five years & 118 & 65.5 \\
\hline Five years and above & 62 & 34.5 \\
\hline \multicolumn{3}{|l|}{ Religion } \\
\hline Orthodox & 96 & 53.3 \\
\hline Muslim & 17 & 9.4 \\
\hline Protestant & 64 & 35.5 \\
\hline Others ${ }^{\circledR}$ & 3 & 1.6 \\
\hline \multicolumn{3}{|l|}{ Educational status } \\
\hline Diploma & 103 & 57.2 \\
\hline $\mathrm{BSc}$ & 76 & 42.2 \\
\hline $\mathrm{MSc}$ & 1 & 0.5 \\
\hline \multicolumn{3}{|l|}{ Ethnicity } \\
\hline Amhara & 72 & 40.0 \\
\hline Oromo & 38 & 21.1 \\
\hline Sidama & 21 & 11.6 \\
\hline Wolayita & 17 & 9.4 \\
\hline Others $\Omega$ & 32 & 17.7 \\
\hline \multicolumn{3}{|l|}{ Marital status } \\
\hline Married & 106 & 58.8 \\
\hline Single & 73 & 40.5 \\
\hline Divorced & 1 & 0.5 \\
\hline \multicolumn{3}{|l|}{ Family history of breast cancer } \\
\hline Yes & 7 & 3.8 \\
\hline No & 173 & 96.2 \\
\hline
\end{tabular}

Others ${ }^{\circledR}$ - Catholics, Wakefeta....

Other $\Omega-$ Dawro, Hadya, Sltie.... 
Table 2: Practice of BSE of female nurses of Hawassa University comprehensive and specialized hospital, south Ethiopia, February $2018(\mathrm{n}=180)$.

\begin{tabular}{|c|c|c|}
\hline Variables & Frequency & Percentage \\
\hline \multicolumn{3}{|l|}{ Have you ever practiced BSE? $(\mathrm{n}=180)$} \\
\hline Yes & 128 & 71.2 \\
\hline No & 52 & 28.8 \\
\hline \multicolumn{3}{|l|}{ Reason to perform BSE $(n=128)$} \\
\hline Had breast problem & 2 & 1.6 \\
\hline Fear of breast cancer from the family & 7 & 5.5 \\
\hline For early detection and treatment of breast cancer & 119 & 92.9 \\
\hline \multicolumn{3}{|l|}{ Reason not to perform BSE $(\mathrm{n}=52)$} \\
\hline Don't had breast problem & 3 & 5.7 \\
\hline Don't thought it is important & 4 & 7.6 \\
\hline Lack of privacy at home & 5 & 9.6 \\
\hline It is not comfortable & 2 & 3.8 \\
\hline Don't know the technique & 38 & 73.1 \\
\hline \multicolumn{3}{|l|}{ How frequently do you perform BSE $(n=128)$} \\
\hline Regularly & 36 & 28.1 \\
\hline Occasionally & 92 & 71.8 \\
\hline \multicolumn{3}{|l|}{ How often do you perform BSE?(n=128) } \\
\hline Weekly & 26 & 20.3 \\
\hline Monthly (correct response) & 21 & 16.4 \\
\hline Ever three months & 23 & 17.9 \\
\hline Annually & 27 & 21.1 \\
\hline \multirow{2}{*}{\multicolumn{3}{|c|}{ When do you do BSE?(n=128) }} \\
\hline & & \\
\hline A time of menses & 38 & 29.7 \\
\hline A day after menses end & 49 & 38.3 \\
\hline A week after menses (correct response) & 41 & 32.0 \\
\hline \multicolumn{3}{|l|}{ Position to perform BSE $(n=128)$} \\
\hline Lying down & 18 & 14.1 \\
\hline Standing in front of the mirror & 22 & 17.1 \\
\hline Showering & 27 & 21.1 \\
\hline All position & 61 & 47.6 \\
\hline \multicolumn{3}{|l|}{ Examination technique used to examine breast $(\mathrm{n}=128)$} \\
\hline Inspection & 20 & 15.6 \\
\hline Palpation & 26 & 20.3 \\
\hline Both inspection and palpation & 82 & 64.1 \\
\hline \multicolumn{3}{|l|}{ Palpation techniques in BSE $(n=128)$} \\
\hline With palm and three middle fingers (best response) & 73 & 57.0 \\
\hline Palpate with any of the fingers & 55 & 43.0 \\
\hline \multicolumn{3}{|c|}{ Sign and symptoms breast cancer looked for while examining the breast $(n=128)$} \\
\hline Presence of mass (best response) & 93 & 72.6 \\
\hline Skin color change & 6 & 4.7 \\
\hline Change in size of breast & 15 & 11.7 \\
\hline Change in nipple & 8 & 6.3 \\
\hline Unusual discharge & 6 & 4.7 \\
\hline \multicolumn{3}{|l|}{ Ever detected a mass/ lump /something abnormal (n=128) } \\
\hline Yes & 7 & 5.5 \\
\hline No & 121 & 94.5 \\
\hline \multicolumn{3}{|l|}{ Immediate action taken after abnormal / a lump detected $(\mathrm{n}=7)$} \\
\hline Consult physician & 3 & 42.8 \\
\hline Ignore & 4 & 57.2 \\
\hline \multicolumn{3}{|l|}{ Reasons for not taking action for the observed problem $(n=4)$} \\
\hline Negligence & 1 & 25.0 \\
\hline Fear of detecting something abnormal & 2 & 50.0 \\
\hline Forgotten & 1 & 25.0 \\
\hline \multicolumn{3}{|l|}{ Ever taught BSE technique to the client? $(\mathrm{n}=128)$} \\
\hline Yes & 21 & 16.4 \\
\hline No & 107 & 83.6 \\
\hline
\end{tabular}


Table 3: Multiple logistic regression analysis results for association between BSE and independent variables among female nurses of Hawassa University comprehensive and specialized hospital, south Ethiopia, February 2018 .

\begin{tabular}{|c|c|c|c|c|}
\hline \multirow[t]{2}{*}{ Characteristics } & \multicolumn{2}{|c|}{ Ever Practiced BSE } & \multicolumn{2}{|c|}{ Odds ratio } \\
\hline & Yes & No & COR $(95 \% \mathrm{CI})$ & AOR $(95 \%)$ \\
\hline \multicolumn{5}{|l|}{ Age } \\
\hline $15-20$ & 3 & 2 & $1.01(0.62,1.6)$ & $1.04(0.57,1.88)$ \\
\hline $21-25$ & 46 & 23 & $0.98(0.45,2.14)$ & $0.73(0.28,1.90)$ \\
\hline $26-30$ & 43 & 14 & $0.97(0.51,1.86)$ & $1.35(0.63,2.8)$ \\
\hline $31-35$ & 21 & 7 & $1.06(0.57,1.97)$ & $1.18(0.50,2.83)$ \\
\hline$>35$ & 15 & 6 & 1.00 & 1.00 \\
\hline \multicolumn{5}{|l|}{ Work experience } \\
\hline Less than five years & 84 & 34 & $0.4(0.28,0.91) *$ & $0.9(0.42,1.97)$ \\
\hline Five years and above & 44 & 18 & 1.00 & 1.00 \\
\hline \multicolumn{5}{|l|}{ Religion } \\
\hline Orthodox & 67 & 29 & $2.4(1.01,6.36) *$ & $1.2(0.36,4.75)$ \\
\hline Muslim & 11 & 6 & $3.2(0.88,12.10)$ & $1.0(0.20,5.95)$ \\
\hline Protestant & 47 & 17 & $3.4(1.13,10.77) *$ & $1.8(0.39,8.88)$ \\
\hline Others & 3 & 0 & 1.00 & 1.00 \\
\hline \multicolumn{5}{|l|}{ Educational status } \\
\hline Diploma & 74 & 29 & $1.40(0.81,2.43)$ & $0.98(0.54,1.77)$ \\
\hline $\mathrm{BSc}$ & 53 & 23 & $2.97(1.83,4.83)^{*}$ & $2.91(1.74,4.85) * *$ \\
\hline MSc & 1 & 0 & 1.00 & 1.00 \\
\hline \multicolumn{5}{|l|}{ Ethnicity } \\
\hline Amhara & 54 & 18 & $1.02(0.63,1.7)$ & $1.05(0.58,1.89)$ \\
\hline Oromo & 31 & 7 & $1.07(0.58,1.98)$ & $1.19(0.51,2.84)$ \\
\hline Sidama & 12 & 9 & $1.41(0.82,2.44)$ & $0.99(0.55,1.78)$ \\
\hline Wolayita & 11 & 6 & $1.73(1.06,2.80)$ & $0.98(0.57,1.70)$ \\
\hline Others & 20 & 12 & 1.00 & 1.00 \\
\hline \multicolumn{5}{|l|}{ Marital status } \\
\hline Married & 73 & 33 & $1.31(0.87,1.96)^{*}$ & $1.32(0.69,2.51)$ \\
\hline Single & 54 & 19 & $1.04(0.50,2.12)$ & $0.91(0.35,2.32)$ \\
\hline Divorced & 1 & 0 & 1.00 & 1.00 \\
\hline \multicolumn{5}{|c|}{ Family history of breast cancer } \\
\hline Yes & 6 & 1 & $6.8(8.08,34.96) *$ & $5.2(2.34,8.15) * *$ \\
\hline No & 122 & 51 & 1.00 & 1.00 \\
\hline
\end{tabular}

Others ${ }^{\circledR}$ - Catholics, Wakefeta....

Other $\Omega-$ Dawro, Hadya, Sltie....

\section{References}

1. D. M. Parkin and L. M. G. Fernandez (2006). "Use of statistics to ' assess the global burden of breast cancer," Breast Journal, vol. 12, supplement 1, pp. S70-S80.

2. P. L. Porter (2009). "Global trends in breast cancer incidence and mortality," Salud Publica de M exico, vol. 51, supplement 2, pp. s141-s146.

3. World health organization (2014). Breast cancer: prevention and control. Available at: http://www.who.int/entity /cancer/detection/en/

4. Ethiopian Cancer Association (2008). Fight against tobacco to reduce the Risk of cancer through Anti-tobacco youth clubs in Ethiopia. Available at: http://www.yeeca.org/Projects.htm

5. Bray F, Ren J-S, Masuyer E, Ferlay J (2012). Global estimates of cancer prevalence for 27 sites in the adult population in 2008. Int J Cancer.

6. IARC WHO (2013) Latest world cancer statistics.

7. Maznah Dahlui, Daniel EngHwee Gan, et al (2012). Predictors of Breast Cancer Screening Uptake: A Pre Intervention Community Survey in Malaysia Asian Pacific Journal of Cancer Prevention.

8. Mary Atanga Bi Suh, Julius Atashili, Eunice Asoh Fuh and Vivian Ayamba etal (2012). Breast SelfExamination and breast cancer awareness in women in developing countries: a survey of women in Buea, Cameroon BMC Research Notes, 5:627.

9. Tavafian SS, Hasani L, Aghamolaei T, Zare S, Gregory D (2009). Prediction of breast self-examination in a sample of Iranian women: an application of the Health Belief Model. BMC Women's Health; 9: 1-7.

10. Özgül Karayurt, Dilek Özmen and Aynur Çakmakçi Çetinkaya (2008). Awareness of breast cancer risk factors 
and practice of breast self-examination among high school students in Turkey BMC Public Health, 8:359.

11. Rosenberg R, Levy Schwartz R (2003). Breast cancer in women younger than 40 years. Int J Fertil Womens Med, 48:200-205.

12. Obaji NC, Elom HA, Agwu UM, et al (2013). Awareness and practice of breast self-examination among market women in Abakaliki, South East Nigeria. Ann Med Health Sci Res; 3:7-12.

13. Astra Zeneca pharmaceuticals (2015), Clinical Oncology Publishes Findings from First-Ever Initiative on Sustainable Breast Cancer Treatment in the Developing World.

14. Kalandar Ameer, et al (2014). Breast Cancer Awareness and Practice of Breast Self-Examination among Female Medical Students in Haramaya University, Harar, Ethiopia International Journal of Interdisciplinary and Multidisciplinary Studies (IJIMS), Vol 2, No.2, 109-119.

15. Chioma C, Asuzu S (2007). Knowledge, attitude and practice of self-breast examination among the female students of the University of Ibadan, Nigeria. Pakistan J Social Sci. 2007;4 Suppl 3:400-2.

16. Arzu T, Aklime D (2007). Assessing the efficacy of a peer education model in teaching breast selfexamination to university students. Asian Pacific of Cancer Prevention;8:481.

17. Olusegun Emmanuel Gabriel, et al. (2016). Awareness and practice of self breast examination among female nurses at the Federal Teaching Hospital Ido-Ekiti, Nigeria. Journal of Public Health in Africa; volume 7:528.

18. Oluwatosin OA (2012). Primary health care nurses' knowledge, practice and client teaching of early detection measures of breast cancer in Ibadan. BMC Nursing; 11:22.

19. Adam etal. (2016). Study to evaluate the knowledge and practices of nurses about breast self-examination (BSE) to screen for breast cancer, in Elmak Nimer University hospital. International Journal of Research Granthaalayah, Vol. 4, No.1 : 27-34.

20. Ghanem S, Glaoui M, Elkhoyaali S, et al (2011). Knowledge of risk factors, beliefs and practices of female healthcare professionals towards breast cancer, Morocco. Pan Afr Med J;10:21.

21. Negeri et al. (2017). Assessment of breast self-examination practice and associated factors among female health professionals in Western Ethiopia: A cross sectional study. Int. J. Med. Med. Sci. Vol. 9(12), pp. 148157.

22. Sreedharan J, Muttappallymyalil J, Venkatramana M, Tomas M (2010). Breast self-examination: knowledge and practice among nurses in United Arab Emirates. Asian Pacifc J Canc Prev. APJCP; 11: 651-4.

23. Ahmad Ayed, et al (2015). Breast Self-Examination in Terms of Knowledge, Attitude, and Practice among Nursing Students of Arab American University/ Jenin Journal of Education and Practice Vol.6, No.4.

24. Getu MA, Kassaw MW, Tlaye KG, Gebrekiristos AF (2018). Assessment of breast self-examination practice and its associated factors among female undergraduate students in Addis Ababa University, Addis Ababa, Ethiopia, 2016. Dove press; Volume 2019:11 Pages 21-28.

25. Azage M, Abeje G, Mekonnen A (2013). Assessment of factors associated with breast self-examination among health extension workers in West Gojjam Zone, Northwest Ethiopia. Int J Breast Cancer :1-6.

26. Srivastava K, Jethani S, Kalthe B, Khilnani PS, Bhawalkar JS, Vyas S (2016). Awareness of Breast Cancer Risk Factors and Practice of Breast Self-Examination among Nurses of Tertiary Care Hospital. Ind J For Comm Med.; 3: 75-78.

27. Carelli I, Pompei LM, Mattos CS, Ferreira HG, Pescuma R, Fernandes CE, Peixoto S (2008). Knowledge, attitude and practice of breast selfexamination in a female population of metropolitan São Paulo. Breast 17(3):270-274.

28. Magdalena Woynarowska-Sołdan et al (2019). Breast self-examination among nurses in Poland and their reparation in this regard. Ann Agric Environ Med. doi: 10.26444/aaem/102762.

29. Adika VO, Joffa PPK, Precious MB, et al (2012). Nurses practices and knowledge of breast self-examination in selected hospitals, Bayelsa State, Nigeria. Int J Trop Med;7: 17-23.

30. Sarfo LA, Awuah-Peasah D, Acheampong E, Asamoah F (2013). Knowledge, attitude, and practice of selfbreast examination among female university students at Presbyterian University College, Ghana. American Journal of Research Communication 1: 395-404.

31. Dalal MN, Sahar HA, Al-Hanouf AA, Abrar AO, Eiman MA (2014). Knowledge, attitude and practice of breast self-examination and breast cancer among female medical students in Taif, Saudi Arabia 4: 69-77.

32. Güleser GN, Ünalan D, Akyldz HY (2009). The knowledge and practice of breast self-examination among healthcare workers in Kayseri, Turkey. Cancer Nurs.; 32: E1 E7.

33. Haji-Mahmoodi M, Montazeri A, Jarvandi S, Ebrahimi M, Haghighat S, Harirchi I (2012). Breast SelfExamination: Knowledge, Attitudes, and Practices Among Female Health Care Workers in Tehran, Iran. Breast J.; 8: 222-5.

34. Reisi M, Javadzade SH, Sharifrad G (2013). Knowledge, attitudes, and practice of breast self-examination among female health workers in Isfahan, Iran. J Educ Health Promot.; 2: 46.

35. Alsaif AA (2004). Breast self-examination among Saudi female nursing students in Saudi Arabia. Saudi Med J.; 25: 1574-8. 
36. SAMBO M.N, etal (2013). knowledge and practice of self-breast examination among female undergraduate students in a northern Nigeria university JMBR: A Peer-review Journal of Biomedical Sciences, Vol. 12 No.2 pp 62-68.

37. Gwarzo UM, Sabitu K, Idris SH (2009). Knowledge and practice of breast-self examination among female undergraduate students of Ahmadu Bello University Zaria, northwestern Nigeria. Ann Afr Med.;8(1):55-58.

38. Alazmi SF, Alkhabbaz A, Almutawa HA, Ismaiel AE, Makboul G, El-Shazly MK (2013). Practicing breast self-examination among women attending primary health care in Kuwait. Alexandria J Med.;49(3):281-286.

39. Kosgeroglu N, et al (2011). Knowledge of women on early diagnosis methods and risk factors for breast cancer in a province of Western Turkey: a descriptive study. Pak. J. Med. Sci. 27(3):646-650. 